\title{
Uso dos Laboratórios de Informática em Escolas do Ensino Médio e Fundamental no Interior Nordestino
}

\author{
Use of Computer Labs in Schools Secondary and Primary in Interior Northeast
}

\author{
Ricardo Holanda Nobre \\ Centro de Ciências e Tecnologia \\ Universidade Estadual do Ceará \\ ricardo.nobre@uece,br
}

\author{
José Alex de Sousa \\ Centro de Ciências e Tecnologia \\ Universidade Estadual do Ceará \\ alexbrawn@gmail.com
}

\author{
Cibelli de Sá Pinheiro Nobre \\ Ciencias Sociales \\ Universidad de Salamaca \\ cibellipinheiro@hotmail.com
}

\begin{abstract}
Resumo A educação vem nas últimas décadas passando por profundas mudanças oriundas da introdução da Tecnologia da Informação em suas práticas pedagógicas, objetivando principalmente a melhoria no processo de ensino-aprendizagem. Tomando por base tais preceitos, o presente artigo tem por objetivo analisar o uso dos Laboratórios de Informática pelos alunos de escolas das redes publicas de ensino no interior nordestino. A metodologia adotada envolveu a aplicação de questionários e entrevistas ao corpo docente, coordenadores dos laboratórios, coordenadores pedagógicos e gestores escolares. Foi possível constatar através da análise dos questionários e entrevistas que existe um déficit muito grande no que se refere à formação daqueles que utilizam ou deveriam utilizar as novas tecnologias. De fato, os alunos não estão desfrutando dos recursos da tecnologia da informação existentes nas escolas, ora porque há problemas estruturais, ora porque não há projetos educacionais estruturados que permita a sua plena utilização. Uma outra contribuição deste artigo é uma comparação entre as entidades municipais e estaduais no que se refere a política pedagógica no uso desta tecnologias. Apesar dos laboratórios de informática não estarem sendo utilizados em sua plenitude, constatou-se que houve melhorias no perfil dos alunos, seja no aprendizado, no comportamento ou em outro aspecto sócio-educacional.
\end{abstract}

Palavras-Chave: Educação, Informativa Educativa, Laboratório de Informática

\footnotetext{
Abstract Education has over the past decades undergoing profound changes arising from the introduction of information technology in their teaching practices, mainly aimed at improving the teaching-learning process. Based on these principles, this article aims to analyze the use of Computer Labs by students from schools of public school systems in the interior Northeast. The methodology involved the application of questionnaires and interviews with faculty, coordinators of laboratories, pedagogical coordinators and school administrators. It was found through the analysis of questionnaires and interviews that there is a very large deficit in relation to the training of those who use or should use new technologies. In fact, students are not enjoying the resources of the existing information technology in schools, sometimes because there are structural problems, sometimes because there is no structured educational projects that enable full utilization. Another contribution of this paper is a comparison between the state and local authorities as regards the educational policy in the use of this technology. Despite the computer labs are not being used to its fullest, it was found that there were improvements in the profile of
} 
students, whether in learning, behavior or other socio-educational aspect.

Keywords: Education, Educational informational, Computer Lab 


\section{Introdução}

O uso das novas tecnologias da informação e comunicação (TIC) está cada vez mais presente em diversas áreas e setores de atuação humana como: indústria petrolífera, biologia molecular, usinas eólicas, entre tantas outras. Estas tecnologias além de trazerem mudanças na estrutura da sociedade, também criam novas formas de geração de riquezas e postos de trabalho. Estas tecnologias também estão inseridas no contexto educacional, sendo necessário analisar e, de certa forma, estruturar a sua utilização como recurso pedagógico e como instrumento facilitador da prática pedagógica.

Neste cenário, o uso da informática educativa na escola visa, principalmente, acelerar, dinamizar e incentivar a aprendizagem. Para [1] o uso do computador na educação somado aos avanços da tecnologia, conduz suas virtudes em direção à melhoria do processo de ensinoaprendizagem. Contudo, sua utilização requer planejamento, objetivando a coerência com as estratégias, os métodos e as técnicas de ensino[2].

A inclusão destas tecnologias, em especial, do computador como ferramenta pedagógica, trouxe uma série de dificuldades que impedem a sua plena utilização, como, por exemplo, a dificuldade de adaptação dos professores na realização de atividades utilizando os laboratórios de informática educativa (LIE). Esta última dificuldade, em específico, se dá por vários fatores, dentre eles a insegurança na operação dos computadores, ausência de capacitação e falta de planejamento frente a inclusão desses novos recursos.

Diante das diversas problemáticas existentes com relação à implantação e manutenção dos LIE, faz-se necessário analisar a situação em que os mesmos estão estruturados, sua utilização, sua gestão e, principalmente, como os mesmos estão sendo inseridos no processo ensinoaprendizagem. Estas questões são de suma importância, principalmente, se tais LIEs estão instalados em regiões carentes, como em localidades do interior da Região Nordeste, historicamente caracterizadas pela escassez de recursos públicos, baixa escolaridade e situação de pobreza e miséria em que vivem parte desta população.

Neste trabalho analisaremos escolas do interior do Ceará, verificando como vem sendo realizada a utilização dos LIEs por parte dos alunos, além de indicar os fatores problemáticos e os benefícios oriundos da sua utilização, o nível de capacitação do professores e dos coordenadores dos laboratórios, os softwares que estão sendo utilizados, além de verificar se a sua utilização está contribuindo ou não para a melhoria do processo de ensinoaprendizagem.
O artigo está estruturado em 5 seções. Na $1^{\text {a }}$ Seção é feita uma introdução ao tema, sendo exposto um contexto sobre a temática e a sua importância. Na $2^{a}$ Seção é realizada uma revisão bibliográfica sobre os principais assuntos a autores que tratam a temática. A $3^{\mathrm{a}}$ Seção abrangerá os procedimentos metodológicos que foram utilizados para coletar as evidências e dados necessários à concreção da pesquisa, incluindo a caracterização da área de estudo, as peculiaridades de cada uma das escolas e o contexto econômico-político-educacional.. $\mathrm{Na} 4^{\mathrm{a}}$ Seção serão apresentando os resultados e abertas as discussões sobre os diferentes fatos observados, e por fim a $5^{\text {a }}$ Seção que tratará das conclusões sobre o tema face aos resultados e considerações apresentados.

\section{Revisão Bibliográfica}

Nesta seção abordaremos os principais assuntos inerentes a temática deste artigo, expondo os diversos pontos de vista dos autores que tratam sobre os mesmos.

\subsection{Educação, Aprendizagem e a Informáti- ca Educativa}

O século XXI se apresenta sob a perspectiva de um mundo novo, de uma nova fase da história humana, na qual a tecnologia assume importância inquestionável na nossa sociedade. $\mathrm{O}$ computador associado à outros recursos de TICs se transforma em uma ferramenta com alta potencialidade para apoiar o desenvolvimento do processo de ensino-aprendizagem dos alunos. Não se trata apenas de saber manusear tal recurso recursos, mas de focar o objetivo do uso deste em situações que promovam a construção do conhecimento.

É inegável que a tecnologia impõe um novo jeito de ensinar e aprender, exigindo assim a sua utilização na maioria das etapas do processo de ensino-aprendizagem. Belloni [3] propõe que se unam educação e tecnologia no sentido de transformar o fazer pedagógico em um saber coerente com o perfil exigido pela sociedade.

Não se tratar de substituir os elementos que até hoje são considerados fundamentais para a escola, como o professor ou livro impresso, pelas novas tecnologias, mas sim de agregar a estes outros recursos, e de repensar a forma de ensino frente a nova realidade.

Cada recurso um destes recursos de TICs apresentam características específicas que deverão ser consideradas pelo professor, frente às necessidades do aluno no processo ensino-aprendizagem. A utilização destes, em específico, do computador, na educação deve estar vinculada as 
necessidades e interesses da escola, de cada aluno, e da comunidade como um todo [4].

Surge o termo Informática Educativa para denominar a inserção das TICs como ferramentas que auxiliam no processo ensino-aprendizagem no ambiente escolar.

Diante desta nova realidade e dos atuais desafios educacionais, urge ressignificar o papel da escola na educação, principalmente ao incorporar estes novos recursos no ambiente escolar. Valente [5] aponta alterações na organização curricular, na utilização dos recursos, nas posturas pedagógicas, nas interações entre professor-alunoconhecimento e na estrutura administrativa. Repensar a sua função significa que a escola deve relegar a sua condição de transmissora e transformar-se em espaço de diálogo, discussão, crítica e da sistematização das informações, tendo em vista a sua verdadeira e precípua função: a construção do conhecimento.

Neste cenário o professor deve estar capacitado no uso destas tecnologias, deve ter conhecimento sobre as potencialidades educacionais que elas propiciam e deve ser capaz de alternar adequadamente as atividades tradicionais de ensino-aprendizagem e atividades que utilizam TICs $[2,5,6]$.

Segundo Valente [5], para que os recursos tecnológicos sejam implantados eficazmente no ambiente educacional, são necessários, além do computador: o software educativo; o professor capacitado para utilizar tais recursos como meio educacional; e o aluno. Dentre estes elementos o professor tem um papel essencial, figurando como elemento catalisador do uso destas no processo de aprendizagem dos alunos [7].

No entanto, esta adaptação ao novo cenário, no qual as TICs estão inseridas no ambiente escolar, possui resistência por parte das pessoas afetadas pela mudança. Isso se deve ao fato da Informática Educativa confrontar o paradigma de ensino jesuítico, até hoje presente no ensino brasileiro, no qual o professor é o elemento central do ensino, reposicionando-o como mediador deste processo, no qual o educando passa a ser a figura chave e o principal responsável pela aprendizagem [7].

Em contraponto, a Informática Educativa não deve fomentar o atrofiamento intelectual, o distanciamento social, o egocentrismo, ao contrário, ela deve ser capaz de formar cidadãos melhores, tanto do ponto de vista moral, quanto intelectual, sem criar barreiras sociais. Para Vieira [8] ao se induzir o computador no ambiente escolar como um meio de aprendizagem não deve deixar que este se torne um artigo de luxo, que venha a gerar adultos egoístas e anti-sociais.

Convém verificar como estas tecnologias são introduzidas no ambiente escolar, em especial, dentro dos proje- tos pedagógicos de ensino.

\subsection{A Informática Educativa no Processo Educacional}

Hoje as TICs são reconhecidas pelo impacto positivo no que concerne ao desenvolvimento educacional, desde que o professor: planeje bem suas aulas, determinando propósitos claros do que pretende alcançar; apresente domínio sobre os recursos que utiliza; e integre corretamente os recursos ao planejamento curricular [2].

De fato, as TICs, fazem a diferença quando são incorporadas dentro do projeto pedagógico de ensino, seja como ferramenta de pesquisa, seja por meio de jogos ou softwares educativos. O conhecimento passa a ser construído pelo binômio professor-aluno, e a reflexão dos alunos ganha importância dentro do processo de aprendizagem. Portanto, é necessário um melhor planejamento pedagógico, de forma a considerar os diversos recursos de TICs disponibilizados no ambiente escolar e que podem ser utilizados para favorecer o ensino-aprendizagem.

A mudança no campo da educação, a partir da inserção das tecnologias, enfatiza a importância do fortalecimento do papel dos professores no que concerne à necessidade de incorporar estes recursos na sua prática pedagógica, auxiliando na aprendizagem dos alunos em diferentes disciplinas e áreas do conhecimento [2, 9]. Elas são um meio para fortalecer um estilo mais pessoal de aprender, no qual os estudantes estão ativamente envolvidos na construção do conhecimento e na busca de respostas para seus problemas específicos [10].

Dentre estas tecnologias destacam-se a Internet, os softwares educativos e os laboratórios de informática educativa (LIE).

A Internet é uma importante ferramenta de intercomunicação entre pessoas, e de divulgação de conhecimento e informação, gerando diversos benefícios no processo educacional, tanto para os professores, quanto para os alunos [5, 8]. Nessa mesma linha, a Internet ainda proporciona a ampliação do conhecimento no mundo do saber/aprender, pois na hora da interação do aluno com a rede mundial de computadores, o mesmo fará uso das habilidades de escolher, pensar, refletir, sugerir, sintetizar, dentre outros.

Os softwares educacionais, por sua vez, possibilitam novas abordagens dentro do processo ensinoaprendizagem, incentivando a interatividade alunocomputador-professor, além de possibilitar/acelerar o aprendizado de determinado conhecimento[5, 11, 12]. A escolha correta dos softwares que serão utilizados é fundamental [5], devendo este possuir uma qualidade didáti- 
co-pedagógica que o torne apto a garantir e obter satisfação e produtividade dos alunos no processo de aprendizagem [1].

No entanto, nenhuma destes dois recursos poderiam ser efetivamente utilizados em um ambiente escolar se não houvesse um local físico especialmente preparado, abrangendo computadores, instalações elétricas, sistemas de climatização e outros equipamentos/recursos pertinentes ao ambiente escolar. São os LIEs.

\subsection{Os Laboratórios de Informática Educati- va}

Com a implantação do Programa Nacional de Informática Educativa (PROINFO), em 1997, deu-se início a uma série de investimentos na área da Informática Educativa, dentre eles a criação de LIEs nas escolas públicas.

Este novo espaço deve ser considerado um ambiente de aprendizagem, cujo objetivo é auxiliar o processo de ensino-aprendizagem, mantendo e ampliando a cultura de informática entre os alunos e educadores, tornando o ensino mais satisfatório, motivante e de fácil entendimento $[1,13]$.

Os LIEs surgiram da necessidade de efetivar a ligação entre o computador e a educação. Neste cenário, [14] avaliou os resultados de uma pesquisa sobre a implementação de projetos de inclusão digital nos laboratórios de informática na cidade de Ipatinga/MG, dando destaque a necessidade de um programa de formação continua dos docentes, de modo a possibilitar que este interaja com os softwares educacionais dentro do plano das disciplinas. [15] por sua vez apontou que os laboratórios de informática vem sendo coordenados, em sua maioria, por professores que possuem pouca carga-horária em sala de aula, e não por professores com formação em informática ou áreas correlatas, o que acaba por gerar um distanciamento, desanimo e insegurança dos demais professores no uso deste equipamento.

Em estudo desenvolvido em escolas do interior de Minas Gerais [16] avaliou o uso dos LIEs determinando que os maiores desafios na utilização dos recursos computacionais está relacionado a inserção destes no projeto pedagógico, bem como o incentivo a apropriação destes recursos por parte dos professores.

No Ceará os LIEs estão implantados em 98\% da escolas estaduais [17]. Apesar do número ser bastante elevado isso, por si só, não garante eficácia, e, nem tão pouco eficiência, dada toda a problemática envolvida. É necessário verificar se os mesmos estão operacionais e como estão sendo utilizados dentro do processo educacional. Não é suficiente apenas a aquisição e disponibilização de todo um aparato tecnológico e de infraestrutura física, se tais recursos não estão sendo utilizados ou se são subutilizados.

Outro ponto a considerar, observado por [18], é com relação a capacitação do docente para utilização destes recursos, uma vez que os mesmos não tem segurança no uso da tecnologia, especialmente, do computador.

Neste novo cenário, a capacitação dos professores para utilização dos computadores e demais recursos de TICs no processo de ensino-aprendizagem torna-se uma premissa básica, uma vez que fornece a estes uma visualização de possibilidades de utilização e dos limites que tais ferramentas possuem $[17,18]$.

Além da necessidades de analise do nível de capacitação dos professores em relação a Informática Educativa é necessário verificar que outros fatores influenciam para o uso efetivo e eficaz dos LIEs.

\section{Metodologia}

A presente pesquisa utilizou algumas metodologias que se complementam e que são utilizadas na literatura correlata. Os procedimentos de coleta de dados incluíram o uso de caderno de anotações de campo, observação, registros audiovisuais, fazendo uso também de entrevistas e questionários.

A pesquisa avaliou escolas públicas da rede municipal e estadual situadas na cidade de Missão Velha, que faz parte do único Geopark da América Latina, e seus distritos, sendo estes integrantes da região metropolitana do Cariri.

Como forma de fortalecer e esclarecer os resultados quantitativos encontrados na pesquisa apresentaremos trechos de algumas entrevistas realizadas. Neste cenário, informamos aos entrevistados que as entrevistas não seriam identificadas, sendo garantido o anonimato das respostas. Esta abordagem visava garantir uma maior liberdade de expressão e de opinião, bem como para evitarmos um viés nas respostas dadas pelos mesmos. Os entrevistados serão identificados através de pseudônimos.

Uma vez definidas as diretrizes básicas da pesquisa iniciamos um levantamento bibliográfico que consistiu em um estudo baseado nas referências literárias, nos documentos e/ou nas narrativas orais que possibilitaram diversas leituras dos fatos e fenômenos relacionados ao tema pesquisado. A seguir estão apresentadas as outras etapas da pesquisa. 


\subsection{Inventário dos Softwares Utilizados nos LIE's}

Para realização desse procedimento, foram utilizadas visitas às escolas em seus LIE's, no horário de aula, sendo levantado junto aos responsáveis os softwares educativos existentes nos laboratórios, utilizando-se uma ficha pré-formatada para realizar a identificação e levantamento de algumas características qualitativas dos softwares (F01 - Ficha de Identificação de Software).

Esta ficha tem questões de múltipla-escolha e perguntas abertas não-subjetivas que buscam identificar o software, sua autoria, seu tipo, o publico alvo, além de uma avaliação qualitativa para determinar as características deste, como, por exemplo, se ele possui pré-requisitos, se oferece feekback, se é iterativo, dentre outras.

Esse procedimento objetiva identificar quais softwares educativos as escolas tinham à disposição e que podiam ser utilizados, bem com em que disciplinas os mesmos poderiam ser utilizados.

\subsection{Verificação da Infraestrutura e Funcio- namento dos LIE's}

Para concretização desta atividade foi realizada uma pesquisa com os coordenadores dos laboratórios de informática das escolas por meio de um questionário (Q01 - Questionário usado para verificação do ambiente dos laboratórios de informática) para verificar a relação aluno-computador, sendo este constituído de perguntas abertas que visavam identificar o coordenador, sua formação, tempo no exercício da função de coordenação dos LIE's, quantidade de computadores disponíveis, dentre outras, além de questões fechadas de múltipla-escolha.

Também foram realizadas entrevistas com estes mesmos coordenadores, objetivando uma análise mais específica sobre sua infraestrutura dos LIE's, seu funcionamento e horário disponível para realização de atividades com os alunos, além da existência ou não de acompanhamento pelo responsável pelos laboratórios.

Esse procedimento foi realizado em diferentes horários de aulas e em dias distintos, sendo realizadas mudanças intencionais do agendamento anteriormente estabelecido com os coordenadores. O objetivo era frustrar tentativas de mascaramento da realidade, de forma a realizar uma análise crítica sobre a infraestrutura dos LIEs que fosse mais verossímil, verificando a sua efetiva utilização pelos alunos, identificando a sua verdadeira estrutura física, regras de utilização e funcionamento.

\subsection{Pesquisa de Campo}

Para pesquisa de campo foi utilizado um questionário (Q02 - Questionário usado para avaliação da utilização dos laboratórios de informática) composto de questões abertas e também de múltipla escolha, sendo as questões elaboradas de forma clara, segundo os objetivos da pesquisa, sendo baseadas nas propostas de $[19,20]$. Com relação ao entendimento, o enunciado e a terminologia seguimos a proposta metodológica de [20].

O questionário foi aplicado a todos os professores das escolas pesquisadas tendo em vista a inaplicabilidade direta aos alunos por dois motivos: a) diversidade de graus educacionais entre os discentes e b) tendência a discrepância de dados para aplicação amostral, dado que os alunos de uma mesma série poderiam ter professores diferentes, com propostas pedagógicas diferentes. Foram excluídos da pesquisa os professores que não estivessem efetivamente exercendo o magistério. A pesquisa foi realizada durante o horário das aulas e mediante a autorização prévia dos diretores das escolas, sendo recolhida logo após o devido preenchimento.

Os objetivos principais foram: (i) verificar o uso desses ambientes tanto pelos professores quanto pelos alunos; (ii) verificar o uso de softwares educativos para dinamizar as aulas; (iii) levantar a existência de projetos que estivessem sendo realizados nos LIE's, e com quais finalidades; (iv) verificar se estavam ocorrendo melhorias no aprendizado dos alunos a partir do uso destes laboratórios; (v) analisar o nível de capacitação dos professores para utilização das tecnologias da informação e comunicação nas escolas.

Também foram realizadas entrevistas de maneira a esclarecer algumas situações detectadas após a análise das respostas constantes no Q2. Estas entrevistas foram realizadas com professores, diretores, coordenadores pedagógicos e outros servidores, sempre preservando a confidencialidade dos dados obtidos no Q2, justamente para evitar repressões sobre os indivíduos participantes da pesquisa.

\section{Resultados e Discussões}

Ao todo foram entrevistados 51 professores, , além de 6 diretores, 6 coordenadores pedagógicos, 6 coordenadores dos laboratórios e outros 15 servidores envolvidos nos processo educacional, conforme detalhado na Tabela 1 . 


\begin{tabular}{l|c|c}
\hline \multirow{2}{*}{ Função } & \multicolumn{2}{|c}{$\begin{array}{r}\text { Quantidade por Rede } \\
\text { de Ensino }\end{array}$} \\
\cline { 2 - 3 } & Estadual & Municipal \\
\hline Professor & 19 & 32 \\
\hline Diretor & 2 & 4 \\
\hline Coordenador Pedagógico & 2 & 4 \\
\hline Coordenador do LIE & 2 & 4 \\
\hline Outro & 4 & 11
\end{tabular}

Tabela 1:Detalhamento dos indivíduos que participaram da pesquisa.

Os questionários Q01 e Q02 foram aplicados apenas aos 6 coordenadores dos LEI's e aos 51 professores, respectivamente.

Para efeito de análise entre as duas redes educacionais (estadual e municipal) separaremos os resultados de maneira a explicitar as diferenças pedagógicas e de política estrutural voltadas e educação, além de segmentar em seções cada aspecto relevante da pesquisa.

\subsection{Situação funcional dos Professores}

As escolas estaduais são compostas em $58 \%$ de professores temporários, situação oposta a da rede municipal, onde $56 \%$ são de professores efetivos.

Tal situação merece destaque ao analisarmos o comportamento destes professores em relação a incorporação do uso de novas tecnologias. A pesquisa apontou que os professores temporários, em sua generalidade, adaptam-se bem as mudanças e estão dispostos a inovação, em especial, a utilização de TICs no processo educacional, em contraponto aos professores efetivos que são avessos à inovação, especificamente em trabalhar com o apoio das tecnologias.

Quando ao nível de escolaridade a maioria deles tem pós-graduação, sendo $74 \%$ para os professores estaduais e $66 \%$ para os professores municipais. Isso significa que eles detêm um conhecimento mais específico o que facilita sua transmissão para os alunos, embora partes destes, somente tenham buscado este aprimoramento para fins de incremento salarial, conforme entrevista pessoal com os professores. Vale destacar que os professores ao realizarem cursos, em especial, pós-graduações lato sensu, tornam-se propensos a assimilar mais rapidamente as mudanças, a trazerem inovações, a estarem mais dispostos a aceitarem o novo.

\subsection{Formação Profissional dos Professores}

Quanto ao nível de formação profissional ambas as redes escolares mostraram diversidade nas áreas de formação dos docentes, não havendo discrepâncias que impliquem em comprometimento do processo ensinoaprendizagem. Ao contrário, tal diversidade intra-escolar propícia uma melhor qualidade no ensino, na medida em que este está lotado na disciplina correta.
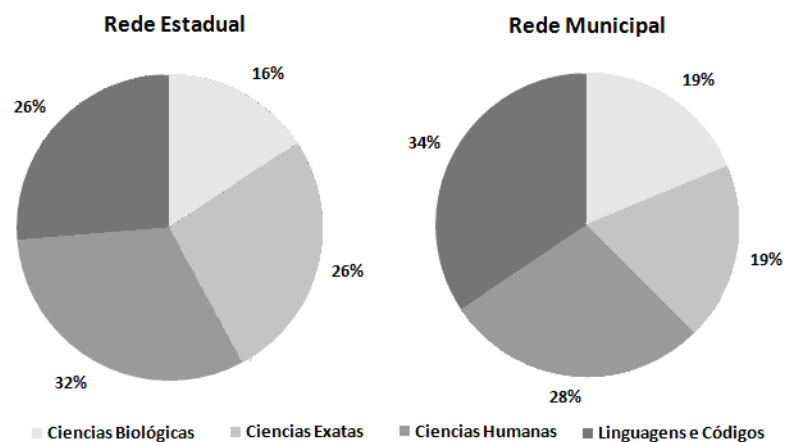

Figura1: Formação Profissional dos Docentes

\subsection{Tempo de Experiência Profissional dos Professores}

A pesquisa também apontou que a maioria dos professores apresenta mais de cinco anos de experiência no magistério, conforme Figura 2.

Pode-se notar na pesquisa que os professores com mais anos no magistério tendem a não buscar o uso de tecnologias com agente facilitador do processo de ensinoaprendizagem.

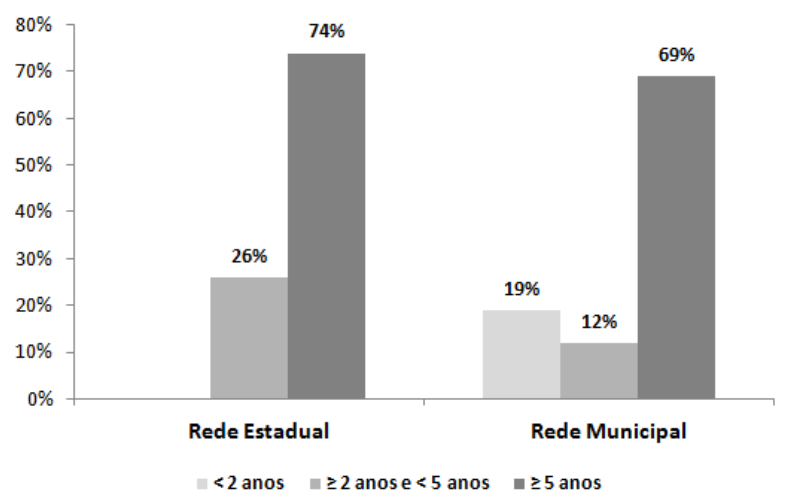

Figura2: Tempo de Experiência na Magistratura

Este distanciamento acaba refletido negativamente nos alunos, colocando-os a margem do processo de evolução digital dentro do próprio ambiente escolar. Esta situação torna-se mais complicada ao se analisar que a utilização dos recursos de informática disponibilizados pela instituição não estar a depender de uma política ou diretriz de ensino, mas apenas da falta de capacitação dos professo- 
res, falta de incentivo da coordenação pedagógica, ou por desvalorização dos professores.

Outro ponto que merece destaque é a quantidade de disciplinas ministradas conforme mostra a Figura 3.

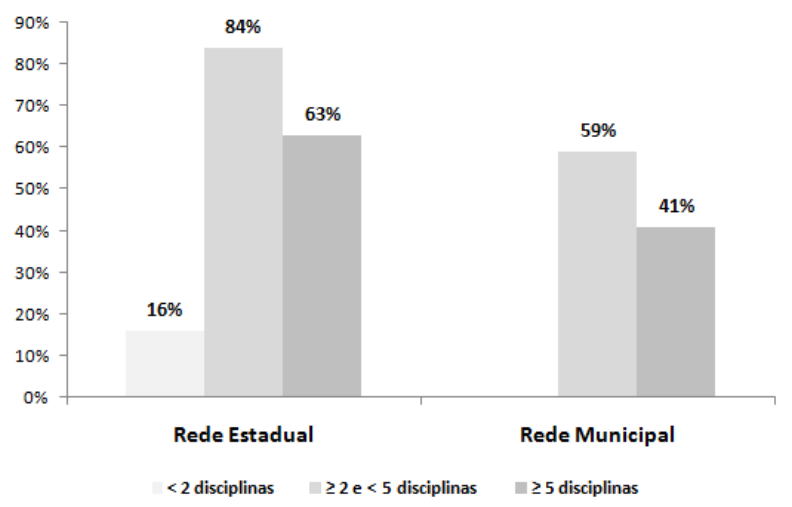

Figura3: Quantidade de disciplinas ministradas pelos Docentes

A maioria dos professores ministram entre duas a cinco disciplinas, porém, na rede municipal nota-se que existem professores que ministram mais de cinco disciplinas, o que pode evidenciar uma sobrecarga de trabalho, vindo a influenciar diretamente no planejamento das aulas e conseqüentemente na qualidade das mesmas, contribuindo, de forma negativa para o processo de aprendizagem dos alunos. Este entendimento também foi descrito em [21], o qual cita o acúmulo de atividades como um dos motivos que levam os professores a não utilizarem os recursos de TICs.

De fato, em algumas entrevistas com professores, foi possível identificar que esta sobrecarga estava prejudicando os mesmos, tanto em relação ao planejamento pedagógico, quanto em relação ao desempenho funcional. Vejamos:

"Ministro 7 disciplinas, e não tenho tempo suficiente para fazer um planejamento adequado das minhas aulas. (...) mal tenho tempo para me reciclar em relação ao conteúdo programático de cada disciplina." (Professor Municipal 01, 2013).

Noutro sentido, o planejamento escolar é fundamental na medida em que os docentes devem analisar o uso desta ferramentas com o intuito de explorar suas potencialidades dentro do processo de aprendizagem, de forma a criar meios eficazes para desenvolver atividades que integrem a informática à educação [11].

Torna-se necessário que as coordenações pedagógicas de instituições com este cenário avalie, de forma criteriosa este aspecto, principalmente, porque foi evidenciada pela pesquisa de que não houve um adequado planejamento que incluísse os recurso de TIC, em específico dos LIEs, nos projetos educacionais promovidos e mantidos pelas escolas que tinham professores nesta situação.

\subsection{Conhecimento dos Professores em Rela- ção a Tecnologia da Informação}

Em meio ao mundo tecnológico em que se encontra o profissional docente, as atuais discussões e políticas públicas na área de informática na educação têm considerado o professor como um componente fundamental para o processo de introdução do computador no cotidiano do ensinar e aprender. É através dos professores que os alunos usam as tecnologias como aliada do conhecimento.

[21] aponta que a formação dos professores no uso das tecnologias é condição primordial para a efetiva implementação destas no âmbito escolar, apontando que esta formação deva ser continuada, contextualizada nas práticas e direcionadas ao desenvolvimento de um professor mais reflexivo.

De acordo com a análise dos resultados obtidos, podese observar que a maioria dos professores da rede estadual receberam capacitação para o uso das tecnologias na escola. Por outro lado, a maioria dos professores da rede municipal estão desatualizados para usufruírem destas tecnologias, conforme Figura 4.

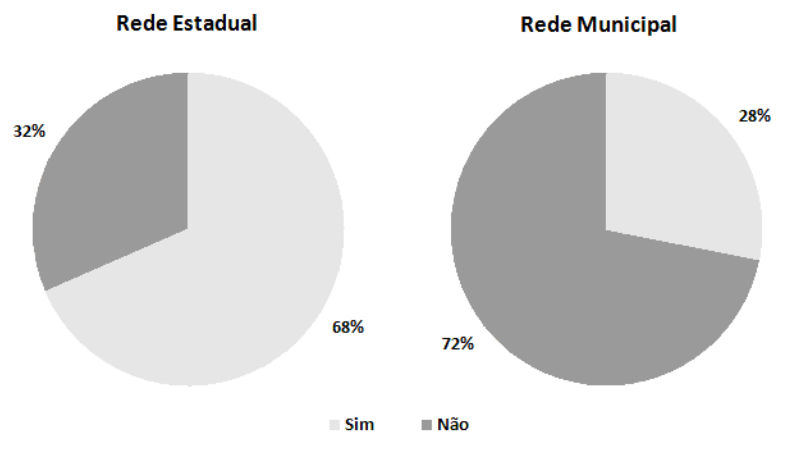

Figura4: Capacitação dos Professores em TI

Dos professores capacitados em TI da rede municipal a maior parte a tinham obtido através de escolas técnicas de informática. Já os professores da rede estadual receberam esta capacitação através de grupos de estudos na própria instituição, conforme evidenciado pela Figura 5. 


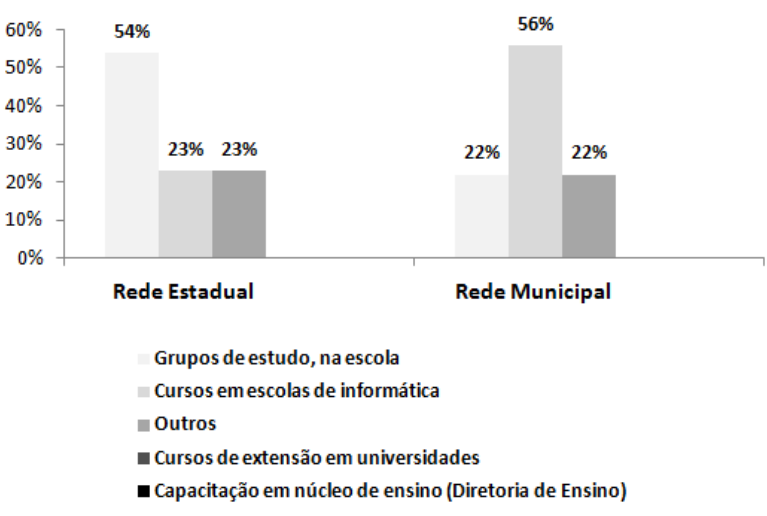

Figura 5: Local de Capacitação dos Professores em TI

Ainda prosseguindo com a análise dos professores que possuíam capacitação em TI, observou-se que a maioria dos professores das escolas pesquisadas receberam a última capacitação em informática a menos de dois anos atrás, conforme Figura 6.

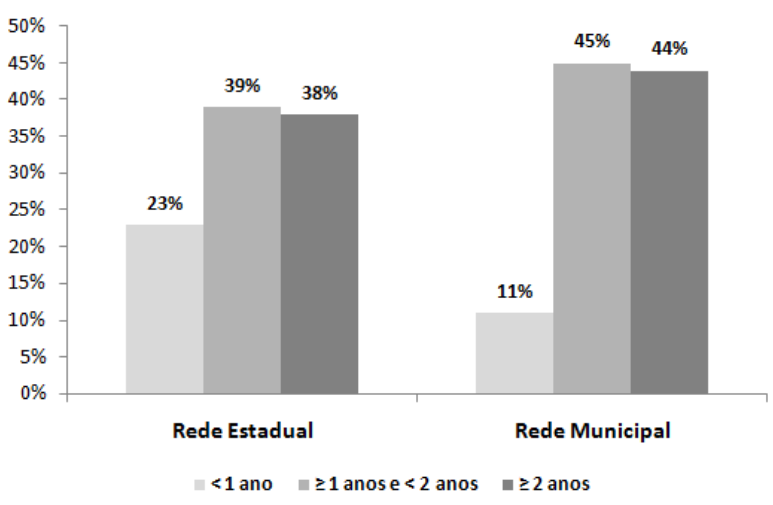

Figura 6: Tempo em que Ocorreu a Última Capacitação em TI

Este dado é importante, na medida em que indica uma formação continuada, porém isso não deve ser analisado isoladamente, principalmente ao se verificar que os professores, embora capacitados, não estão usufruindo deste conhecimento com os seus alunos, pelos mais variados motivos, aos quais apontaremos.

\subsection{Utilização dos Laboratórios de Informá- tica}

A Figura 7 mostra o nível de utilização dos LIEs pelos professores de ambas as redes escolares, sendo que os professores da rede estadual utilizam tais locais, em sua maioria, de uma a três horas por semana, destinando este tempo para participar de atividades em grupos de estudo ou desenvolver atividades com os alunos mesmo sem a existência de um projeto direcionado. Já $69 \%$ dos professores da rede municipal não utilizam os LIEs.

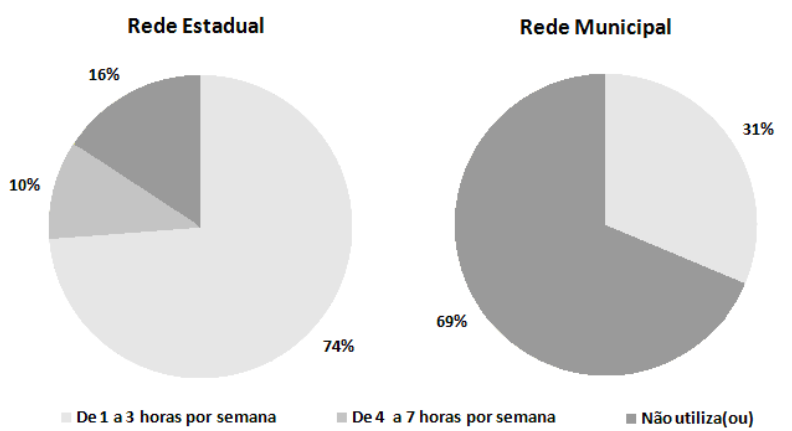

Figura 7: Utilização dos LIEs pelos Professores

Neste contexto os alunos sofrem conseqüências diretas, na medida que o processo de aprendizagem poderia ter sido facilitado se os professores tivessem adotado os recursos de TIC em suas aulas.

Dentre as principais razões da não utilização dos LIEs destaca-se a insegurança em trabalhar com TI e a falta de incentivo por parte da coordenação pedagógica, o que de certa forma são reflexos da falta de capacitação dos professores em TIC e da ausência de políticas de incentivo no uso de recursos tecnológicos como ferramenta de apoio ao processo de aprendizagem, tanto no nível das unidades educacionais avaliadas, quando no nível das políticas educacionais, por parte dos governantes, conforme mostrado na Figura 8.

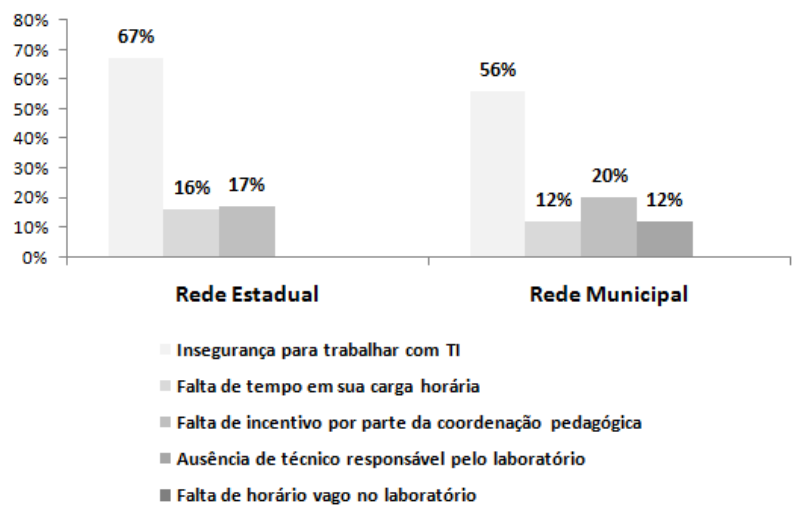

Figura 8: Motivos que impedem ou dificultam os Professores de utilizar os LIEs

De fato, é extremamente fundamental que os gestores educacionais sejam conscientizados e sensibilizados da importância das TICs no processo educacional, principalmente através do incentivo [14].

Ainda sobre este aspecto citamos o relato de um pro- 
fessor da rede municipal:

"Sinto dificuldade em utilizar o laboratório de informática com os alunos, principalmente porque não domínio bem a informática, e as vezes que procurei utilizar o laboratório não encontrei ninguém que me ajudasse. (...) não há um apoio técnico que efetivamente nos ajude. $\mathrm{O}$ coordenador do laboratório é um professor que foi designado por ter uma maior conhecimento da informática, mas não é um especialista. Tenho receio" (Professor Municipal 02, 2013).

De fato, esta ausência de um coordenador de LIE com conhecimento técnico especializado vêm sendo apontado como um dos fatores que dificultam a utilização dos mesmos, dado que os professores se sentem desamparados e inseguros no uso deste recurso[15].

Complementando este cenário trazemos um trecho que aponta outro problema advindo da não utilização dos LIEs, que se trata do apoio institucional.

"Não utilizo o laboratório por um simples motivo: não há um direcionamento por parte da direção que isso seja importante. Se fosse realmente importante estaria na definição do plano pedagógico. Não há qualquer iniciativa institucional que leve o professor e os alunos ao laboratório" (Professor Estadual 01, 2013).

Este relato foi repetido por outros professores, das duas redes de ensino e merece atenção, pois um dos primeiros passos para uma correta utilização dos LIEs passa pela gestão escolar e pedagógica, conforme [14], na medida em que estes entendem a importância deste recurso para o processo de ensino-aprendizagem, levando-os a planejar ações que concretizem a utilização correta dos recursos tecnológicos existentes nas escolas.

A pesquisa mostrou que apenas uma parte da utilização dos LIEs pelos docentes está vinculada à atividades diretas com alunos (Figura 9). Outro ponto de destaque é a ausência de projetos educacionais que envolvam, desde a sua concepção, os LIEs, ou seja, os professores que desenvolve atividades com os alunos nos laboratórios, o fazem sem um projeto educacional previamente definido. Este fato em si contribui para a subutilização destes recursos no processo ensino-aprendizagem.

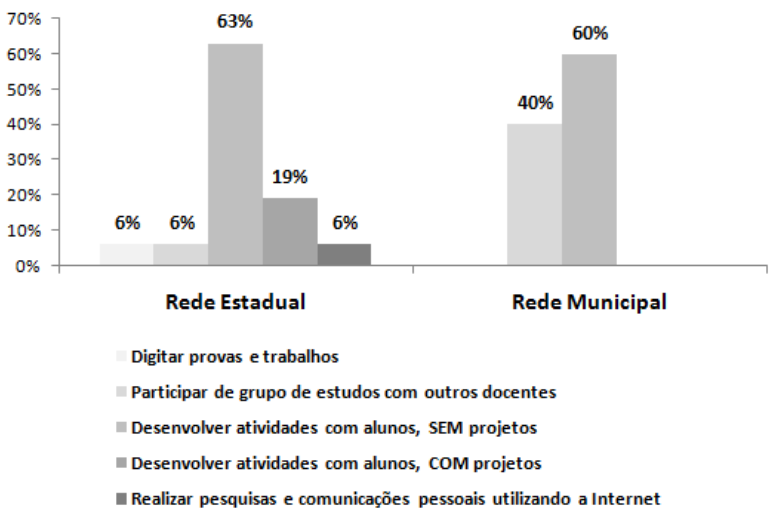

Figura 9: Finalidade da utilização dos LIEs pelos professores

\subsection{Uso de Softwares Educativos para Aper- feiçoamento da Aprendizagem dos Alu- nos}

A pesquisa apontou que a maioria dos professores das escolas pesquisadas não utilizam a totalidade dos softwares educativos disponíveis com seus os alunos. Este problema é causado pela falta de capacitação dos professores para utilizarem os recursos disponíveis da escola, pela ausência de interesse dos próprios professores em buscar algo novo, além da ausência de interesse por parte das coordenações pedagógicas na condução de ações que visem a elaboração de projetos com o foco na utilização do laboratório de informática e demais recursos de TICs. O problema tem maior gravidade na rede municipal, conforme demonstra a Figura 10.
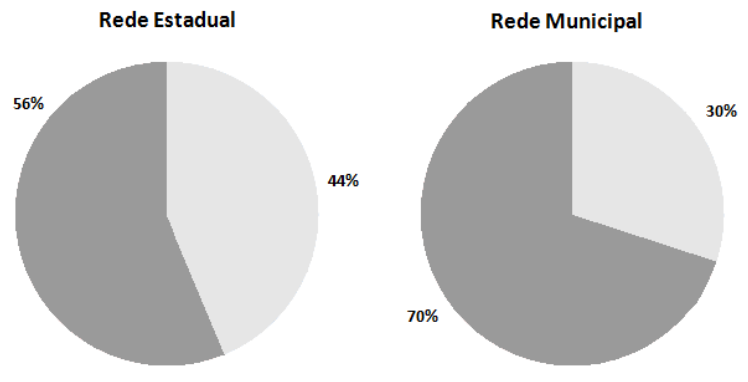

Utilizam todos os softwares disponiveis

= Não Utilizam todos os softwares disponiveis

Figura 10: Utilização dos Softwares Disponíveis pelos Alunos.

Além da baixa adesão dos professores a utilização dos softwares educacionais com os seus alunos, ainda temos o problema relacionado a diversidade dos softwares utilizados. Foi constatado entre os professores que usam estes recursos, que esta utilização está limitada, em grande parte, a apenas um único software (Figura 11). 


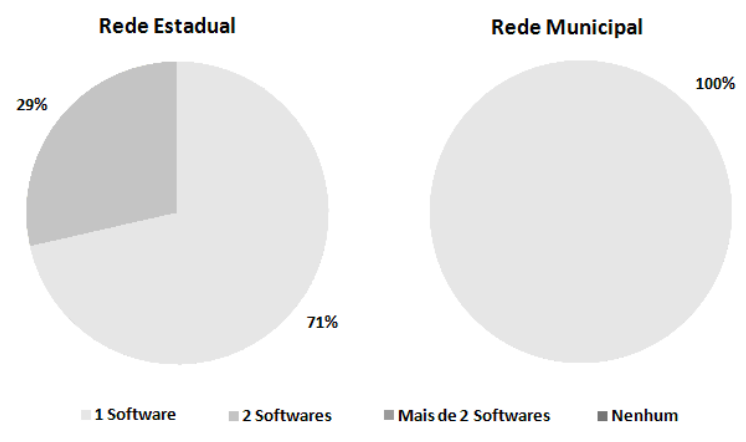

Figura 11: Quantidade de Softwares Educativos utilizados pelos Professores com seus alunos.

Isto se deve a alguns fatores como: inexistência de outros softwares educativos nas escolas e que possam ser utilizados para ministrar ou fixar determinando conteúdo; falta de conhecimento sobre os softwares existentes; ausência de iniciativa dos professores e a ausência de uma proposta pedagógica capaz de propor novas aplicações.

Faz-se necessário uma avaliação pelos coordenadores pedagógicos de ambas as redes escolares sobre as necessidades existentes, bem como em relação à capacitação do corpo docente, uma vez que a não utilização dos laboratórios e dos softwares educacionais refletem diretamente na qualidade do ensino disponibilizado aos alunos.

Como ponto positivo foi possível constatar, junto aos professores que utilizaram softwares educativos com seus alunos, que houve uma mudança positiva no comportamento e na aprendizagem dos mesmos. Evidenciou-se que as aulas tornaram-se mais atrativas, despertando o interesse e a curiosidade dos alunos. A Figura 12 mostra as melhoras percebidas por estes professores.

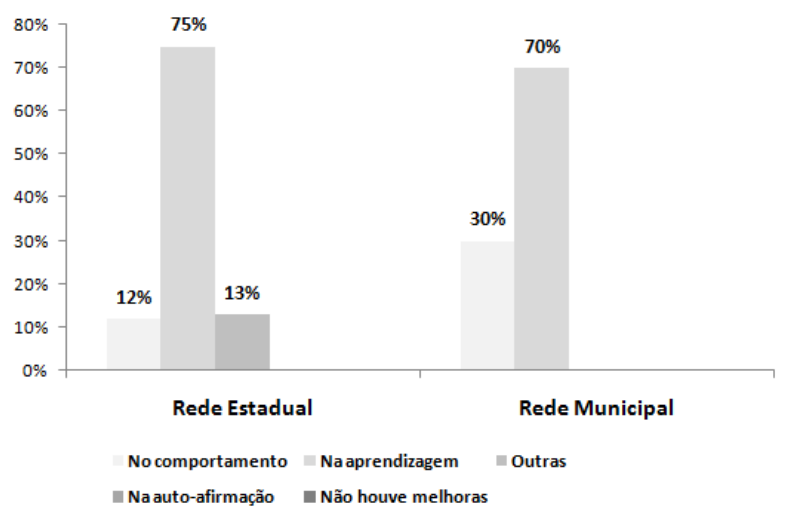

Figura12: Melhora dos Alunos após Utilização dos LIEs

De fato, esses achados encontram sustentáculo em outros já existentes na literatura, como em [16].

Vejamos os relatos de professores das duas redes de ensino que evidenciam os ganhos obtidos com o uso de softwares educativos:

"A aprendizagem propiciada pelos softwares educativos nos alunos é evidente. Eles saem daquela rotina da sala de aula convencional e exercitam com os aplicativos o que foi visto na sala. Os resultados são muito bons. $\mathrm{O}$ próprio comportamento do aluno muda. Ele espera ansioso o dia da aula no laboratório de informática" (Professor Estadual 02, 2013).

"Percebi tanto uma mudança no comportamento dos alunos, quando na aprendizagem. A tencologia, neste aspecto, está agregando muito a escola, ao professo, e principalmente aos alunos" (Professor Municipal 03, 2013).

\subsection{Tipos de Software Educativos Existentes nos LIEs}

Seguindo com a análise dos dados, observou-se que a grande maioria dos professores das redes escolares adotam softwares do tipo exercitação com os alunos, conforme Figura 13. Esta escolha deve-se principalmente ao fato deste tipo de software se prestar bem ao papel de fixação do conteúdo visto em sala de aula, como também pode estar relacionada a falta de capacitação dos docentes quanto aos recursos disponíveis nos laboratórios.

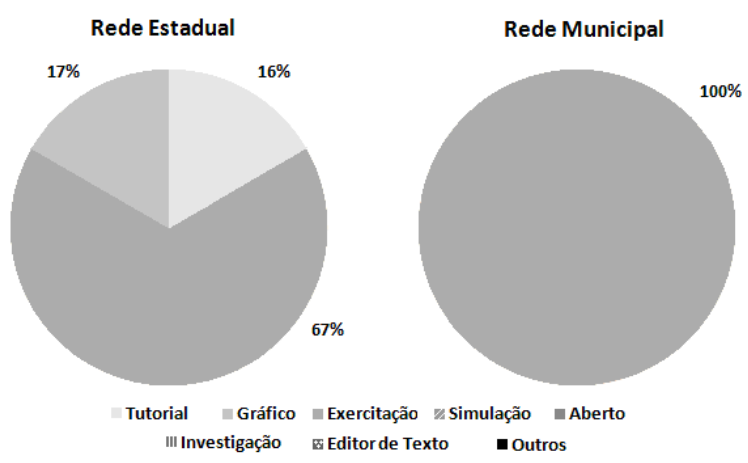

Figura13: Tipos de Softwares Educativos Usados pelos Professores

Quanto à qualidade destes softwares, a maioria dos professores das escolas declararam que eles são interativos, as telas, os gráficos e os textos são adequados para utilização, que os mesmos oferecem feedback, possuem níveis de dificuldades e são simples de usar,, além do fato de não possuir requisitos para a sua utilização, conforme Figura 14. São, portanto, ideais, pois possuem o que é necessário e indispensável ao processo de aprendizagem. 


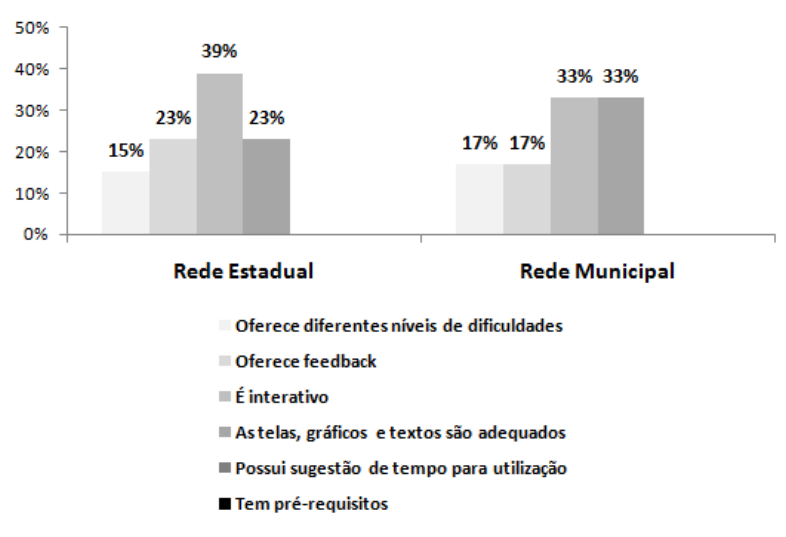

Figura14: Qualidade dos Softwares Educativos

\section{Conclusão}

Na medida em que se reconhece a verdadeira realidade das escolas como espaços de formação dos cidadãos e também, de inclusão digital, torna-se fundamental analisar e refletir sobre o funcionamento das novas tecnologias da informação, disponíveis ao processo de ensinoaprendizagem, em especial, dos LEIs.

No contexto da sociedade da informação e do conhecimento, espera-se que os educadores assumam novas atitudes, repensem suas práticas pedagógicoadministrativas, elaborem e operacionalizem projetos educacionais colaborativos utilizando todas as potencialidades das TICs.

É preciso entender as necessidades dos alunos, o contexto social, a realidade da escola e a sua intencionalidade pedagógica. Para tanto, devem priorizar algumas atitudes que favoreçam a incorporação da tecnologia da informação no processo educacional como ferramenta potencializadora do processo educacional

O uso do computador, em especial, dos laboratórios de informática como ferramenta educacional pode vir a favorecer o ensino e a aprendizagem, no entanto, requer uma mudança cultural, principalmente por aqueles que gerem e por aqueles que lecionam.

O cenário montado pelos dados coletados na pesquisa através da realização de entrevistas, observações e questionários apontou uma realidade na qual os professores ainda não estão adaptados ao mundo das tecnologias da informação no ambiente escolar, o que interfere diretamente no uso dos laboratórios de informática pelos alunos.

Verificou-se que os alunos não utilizam os softwares educacionais porque os professores não utilizam o laboratório de informática ou quando o fazem é para outros propósitos, além do fato de não existirem projetos educacionais nos quais os recursos de TIC tenham sido inseridos quando do planejamento das disciplinas.

O corpo docente, por sua vez, precisa ter uma visão mais ampla na qual os LEIs constituem um espaço a mais para o desenvolvimento de seu trabalho, bem como se faz necessário que haja uma capacitação mais adequada para utilização destes recursos.

Deste modo, conclui-se que para haver uma mudança no ambiente escolar, com relação ao uso da informática como elemento facilitador e fomentador do processo de aprendizagem, e de que as TICs podem trazer mudanças positivas na organização do ensino, faz-se necessário que a gestão escolar e os docentes estejam conscientes deste papel.

Para tanto, seria importante que os professores, coordenadores pedagógicos e gestores das instituições de ensino participassem, de maneira mais efetiva e direta, do processo de mudança proveniente da introdução das TICs no ambiente escolar, estando consciente da importância de tais mudanças para melhoria do aprendizado dos alunos.

Como trabalhos futuros sugere-se a ampliação desta pesquisa de maneira a envolver redes escolares de outras regiões, comparando-as. Outro trabalho promissor seria uma investigação sobre a necessidade de implementação de objetos virtuais de aprendizagem (OVA) para o ensino de disciplinas relacionadas às ciências exatas, vinculadas ao ensino fundamental e médio, tendo em vista que os alunos, em geral, têm deficiências de aprendizado nestas áreas do saber.

\section{Referências}

[1] D. F. Grzesiuk. O uso da informática na sala de aula como ferramenta de auxilio no processo ensino-aprendizagem. Monográfica de Especialização em Métodos e Técnicas de Ensino, Universidade Tecnológica Federal do Paraná, Nov 2008.

[2] F. M. P. Freire, M. E. B. B. Prado, M. C. Martins, O. Sidericoudes. A implantação da informática no espaço escolar: questões emergentes ao longo do processo. Revista Brasileira de Informática na Educação, 3: 45-62, 1998.

[3] M. L. Belloni. Educação à Distância. 5a. ed. Campinas, SP: Autores Associados, 2008.

[4] R. G. Miranda, J. P. Camossa. O uso da informática como recurso pedagógico: um estudo de caso. http://www.planetaeducacao.com.br/ por- 
tal/ vozdoprofessor/usouso-da-nformatica-comorecurso-pedagogico.pdf. Jan. 2013.

[5] J. A. Valente. O computador na sociedade do conhecimento. UNICAMP/NIED, São Paulo, 1999.

[6] C.C. Silva. A Informática Educativa e as dificuldades de aprendizagem na Educação Infantil. Monográfica de Especialização em Tecnologia Educacional, Universidade Candido Mendes, Jul 2005.

[7] S. S. D. Rocha. O uso do Computador na Educação: a Informática Educativa. Revista Espaço. Acadêmico, 85: 1-6, 2008.

[8] Z. N. L. Vieira. A Informática na Educação. Rio de Janeiro: Monográfica de Especialização em Tecnologia Educacional, Universidade Candido Mendes, Jul 2006.

[9] J. C. Tedesco. Educação e Novas Tecnologias: esperança ou incerteza? São Paulo: Cortez, 2004.

[10] J. M. Sancho, F. Hernández. Tecnologias para transformar a Educação. Porto Alegre: Artmed, 2006.

[11] K. A. S. Nascimento, M. S. S. Lima, J. A. Castro Filho. Um olhar sobre as atividades dos Laboratórios de Informática Educativa das escolas municipais de Fortaleza. In Anais do XXII SBIE XVII WIE, Aracaju, páginas 1256-1263, 2011.

[12] S. C. S. Jucá. A relevância dos softwares educativos na educação profissional. Ciências \& $\mathrm{Cog}$ nição, 8: 22-28, 2006.

[13] T. E. Macedo. Subsídios Pedagógicos para o uso do Laboratório de Informática. IES: UEPG, 2008 .

[14] M. F. V. Borges. Inserção da Informática no Ambiente Escolar: inclusão digital e laboratórios de informática numa rede municipal de ensino. In WIE. Anais do XXVIII Congresso da SBC, Belém, PA, páginas 146-155, 2008.

[15] R. Costa, V. Barros, J. Pinto, J. Silvestre, L. Neiva, A. Thereza Jr. Internet e Laboratório de Informática: Dois Importantes Recursos Metodológicos para Surpreender os Estudantes e Beneficiar a Interdisciplinaridade. In XX SBIE. Anais do XX SBIE, Florianópolis, 2009.

[16] E. K. Odorico, D. M. Nunes, A. Moreira, H. M. P. Oliveira, A. Cardoso. Análise do não uso do laboratório de informática nas escolas públicas e estudo de caso. In Anais do XVIII WIE, Rio de
Janeiro, 2012.

[17] E. M. Vidal, G. K. F. Ferreira, J. E. B. Maia. Estágio Supervisionado em Informática. Fortaleza: UAB/UECE, 2011.

[18] V. F. S. Moura, M. F. P. A. Pedra, A. M. X. Santos. Formação de professores e as tecnologias educacionais: como está sendo o uso do computador e laboratórios de informática no ensino fundamental básico. http://www.artigonal.com/educacaoartigos/formacao-de-professores-e-astecnologias-educacionais-como-esta-sendo-ouso-do-computador-e-laboratorios-deinformatica-no-ensino-fundamental-basico5038489.html. Fev. 2013.

[19] E. N. de Oliveira. A utilização dos Laboratórios de Informática do PROINFO em Escolas de Dourados - MS. Dissertação de Mestrado em Engenharia da Produção, Universidade Federal de Santa Catarina. Ago 2001.

[20] M. C. R. A. Joly, M. A. Silveira. Avaliação Preliminar do Questionário de Informática Educacional (QIE) em Formato Eletrônico. Psicol. estud. [online], 8(1):85-92, 2003.

[21] A. C. Fernandes, R. S. Freire, J. A. Castro Filho. Tecnologia na Escola: Um modelo de Implementação a partir da Formação de Professores. In Anais do XV WIE, Bento Gonçalves, páginas 1836-1846, 2009. 